\title{
PENERAPAN METODE CONSPECTUS UNTUK MENGUKUR INTENSITAS KOLEKSI MONOGRAF DI BADAN PERPUSTAKAAN DAERAH PROPINSI DAERAH ISTIMEWA YOGYAKARTA PERIODE PENGADAAN TAHUN 2003
}

\author{
NILAM BADRIYAH
}

\begin{abstract}
"The Application of Conspectus Method to Measure The Intensity of Acquisition for Monograph Collection at Badan Perpustakaan Daerah Propinsi Daerah Istimewa Yogyakarta period 2003" is the main purpose of this study. The writer formulates three main problems, that is how to apply conspectus method, how to know the intensity of monograph collection, and how to understand strength and weakness of the monograph collection at Badan Perpustakaan Daerah Propinsi Daerah Istimewa Yogyakarta. The type of this study is a quantitave description research. The main classification of monograph collection $000-900$ period 2003 is as a subject and Badan Perpustakaan Daerah Propinsi DIY is as an object. The sampling was taken $50 \%$ from the total population. The variable researched is the distribution of classification, strength and weaknesses of the collection, the chronological and language analysis. The method of searching are field research, observation, interview guide and inside evaluator. Data analysis is the process to describe the collected data during this research. Then the result is applied toward conspectus method based on $1-5$ and language code. Conspectus method is to value library collection based on subject area and to describe the srength and weaknesses of the collection, and to know collection level at library. The result of the study indicates that the Badan Perpustakaan Daerah Propinsi DIY has not applied yet the conspectus method to value strength and weakness of the monograph collection it only uses statistics of acquisition for monograph collection. The intensity of acquisition for the monograph collection is high, it is on classification 300 (social science) and classification 000 (general literature) the result of the inside evaluator is $1 \mathrm{~b}$ to 2a. 1a (Minimal Level) means the library has a limited core literatur, however it has amount of literature written by main writers. 2a (basic Information Level) means that core material is available to define a subject. Chronological inclusion of monograph collection is relevant, because the needs modern information mainly is $10 \%$. Material literature published in 2003 is $28 \%$. Language analysis of monograph collection is $\mathrm{Y}$, it means the literature material is dominated by one language, except English.
\end{abstract}

Key word : Conspectus, Intensity of Collection Acquisition

\section{ABSTRAK}

"Penerapan Metode Conspectus untuk Mengukur Intensitas Pengadaan Koleksi Monograf pada Badan Perpustakaan Daerah Propinsi Daerah Istimewa Yogyakarta periode 2003" merupakan tujuan utama dari penelitian ini. Penulis membagi ke dalam 3 masalah utama, yaitu bagaimana menerapkan metode conspectus, bagaimana mengetahui intensitas koleksi monograf, dan bagaimana memahami kekuatan dan kelemahan koleksi monograf pada Badan Perpustakaan Daerah Propinsi Daerah Istimewa Yogyakarta. Jenis penelitian ini adalah penelitian deskripsi kuantitatif. Klasifikasi utama dari koleksi monograf 000 - 900 periode 2003 merupakan subjek penelitian dan Badan Perpustakaan Daerah Propinsi DIY merupakan objek penelitian. Sampel diambil $50 \%$ dari total populasi. Variabel yang diteliti adalah distribusi klasifikasi, kekuatan dan kelemahan koleksi, analisis secara kronologis dan bahasa. Metode yang digunakan adalah penelitian lapangan, observasi, pedoman wawancara dan "inside evaluator". Analisis data merupakan proses untuk mendeskripsikan data yang terkumpul selama penelitian ini. Selanjutnya hasilnya diaplikasikan berdasar metode conspectus berdasar kode 1 - 5 dan bahasa. Metode Conspectus adalah menilai koleksi perpustakaan berdasarkan subjek area dan mendeskripsikan kekuatan dan kelemahan koleksi, dan mengetahui tingkatan koleksi di perpustakaan. Hasil penelitian mengindikasikan bahwa Badan Perpustakaan Daerah Propinsi DIY belum menerapkan metode conspectus untuk menilai kekuatan dan kelemahan koleksi monograf. Hanya menggunakan statistik pengadaan dari koleksi monograf. Intensitas pengadaan koleksi monograf tinggi, Pada klasifikasi 300 (ilmu sosial) dan klasifikasi 000 (literatur umum) hasil "inside evaluator" adalah 1b sampai dengan 2a. 1a (minimum level) menunjukkan perpustakaan mempunyai "core literatur" yang terbatas, bagaimanapun hal itu menunjukkan jumlah literatur yang ditulis oleh penulis utama. $2 \mathrm{a}$ (basic Information Level) maksudnya bahwa "core material" tersedia menjelaskan sebuah subjek. Secara kronologis pemasukan koleksi monograf cukup relevan, karena kebutuhan informasi modern utamanya adalah $10 \%$. Bahan pustaka yang diterbitkan pada tahun 2003 adalah $28 \%$. Analisis bahasa dari koleksi monograf adalah $Y$, ini menunjukkan bahan pustaka didominasi oleh satu bahasa, kecuali bahasa Inggris.

Key word : Conspectus, Intensitas Pengadaan Koleksi 


\section{PENDAHULUAN}

\section{Latar Belakang}

Perpustakaan merupakan salah satu sarana pelestarian bahan pustaka sebagai hasil budaya dan berfungsi sebagai sumber informasi ilmu pengetahuan, teknologi, dan kebudayaan. Perpustakaan harus memiliki sumber daya manusia sekurang-kurangnya seorang pustakawan, ruang atau tempat dan koleksi bahan pustaka yang terdiri dari berbagai disiplin ilmu yang sesuai dengan jenis dan misi perpustakaan yang bersangkutan serta dikelola menurut sistem tertentu untuk keperluan penggunanya. (Perpustakaan Nasional RI, 2005 : 4). Agar fungsi dan tugas perpustakaan terlaksana dengan baik maka diperlukan sumber daya manusia yang berkualitas serta memegang peranan penting dalam seluruh kegiatan perpustakaan dengan didukung keahlian di bidang perpustakaan.

P. Sumardji (1992: 14) menyatakan karena adanya bermacam-macam golongan pemakai yang memanfaatkan perpustakaan dapat diarahkan untuk bermacam-macam tujuan atau kebutuhan, sedangkan bukupun ada bermacam-macam sesuai dengan bidang ilmunya. Begitu juga dengan macam-macam perpustakaan meliputi Perpustakaan Negara, Perpustakaan Daerah, Perpustakaan Perguruan Tinggi, dan Perpustakaan Khusus. Perpustakaan Daerah merupakan perpustakaan yang ada di setiap propinsi. Perpustakaan Daerah yang berlokasi di kota Yogyakarta yaitu Badan Perpustakaan Daerah Propinsi Daerah Istimewa Yogyakarta merupakan objek penelitian. Badan Perpustakaan Daerah Propinsi DIY merupakan penyedia koleksi sebagai bahan referensi bagi siapa saja yang membutuhkan informasi serta koleksinya diatur sistematis sehingga dapat dimanfaatkan sebagai sumber informasi oleh para pengguna.
Secara teknis, kegiatan perpustakaan antara lain pengadaan bahan pustaka, pengolahan bahan pustaka, penyajian bahan pustaka, pemeliharaan dan perawatan bahan pustaka. Kegiatan perpustakaan dalam penelitian ini adalah pengadaan bahan pustaka.

Menurut Nuraini (1998: 18) kegiatan pengadaan penting bagi suatu perpustakaan dalam rangka memperluas dan membangun koleksi yang kuat untuk kepentingan pemakai. Pelaksanaan kegiatan pengadaan bahan pustaka ini harus dilakukan oleh orang yang berpengalaman Iuas tentang bahan pustaka, terampil dalam urusan administrasi, memahami fungsi dan tujuan perpustakaan. Mereka harus mampu mengelompokan koleksinya sesuai dengan bentukbentuknya seperti bentuk monograf dan bentuk non buku. Bentuk monograf adalah monograf adalah wadah informasi yang berwujud lembaran kertas yang dicetak, dan diikat bersama punggungnya serta diberi sampul (Soeatminah, 1992: 21)

Berkaitan dengan kebutuhan pengguna, maka perpustakaan harus mengetahui kebutuhan pengguna. Dalam hal ini perpustakaan perlu mengukur tingkat koleksi standar yang ada pada perpustakaan yang lain. Akan tetapi sulitnya memperkirakan kondisi koleksi buku tiap-tiap perpustakaan merupakan suatu persoalan. Begitu juga dengan koleksi yang ada di Badan Perpustakan Daerah Propinsi DIY. Meskipun dapat diketahui kekuatan yang ditandai dengan kedalaman dan kelengkapan serta kelemahan koleksi tetap diperlukan evaluasi koleksi. Banyak cara dalam evaluasi koleksi antara lain model conspectus menurut Matheson (1987: 22) yaitu sebuah penilaian terhadap koleksi-koleksi perpustakaan secara sistematis berdasarkan area subjek serta mendeskripsikan kekuatan dan kelemahan koleksi-koleksi yang ada.

Alasan lain yang mempengaruhi penulis untuk mengadakan penelitian di Badan Perpustakaan Daerah Propinsi DIY bahwa dengan metode conspectus 
periode pengadaan tahun 2003, karena pengadaan tahun sesudah 2003 (mutakhir) belum tercatat secara lengkap.

\section{RUMUSAN MASALAH}

Berdasarkan latar belakang di atas, maka diperoleh rumusan permasalahan sebagai berikut:

1. Bagaimana penerapan metode Conspectus di Badan Perpustakaan Daerah Propinsi DIY ?

2. Bagaimana intensitas koleksi monograf di Badan Perpustakaan Daerah Propinsi DIY ?

3. Bagaimana kekuatan dan kelemahan koleksi monograf di Badan Perpustakaan Daerah Propinsi DIY?

\section{TUJUAN DAN MANFAAT}

\section{Tujuan}

a. Untuk mendeskripsikan koleksi monograf yang ada di Badan Perpustakaan Daerah Propinsi Daerah Istimewa Yogyakarta tahun 2003

b. Untuk mengukur intensitas koleksi monograf di Badan Perpustakaan Daerah Propinsi Daerah Istimewa Yogyakarta tahun 2003

c. Melakukan pemetaan kekuatan dan kelemahan koleksi monograf yang ada di Badan Perpustakaan Daerah Propinsi Daerah Istimewa Yogyakarta tahun 2003

\section{Manfaat}

Manfaat yang akan diperoleh dari penelitian ini, antara lain:

a. Peneliti

Dapat meneliti dan menerapkan metode conspectus terhadap koleksi monograf di Badan Perpustakaan Daerah Propinsi Daerah Istimewa Yogyakarta tahun 2003.

\section{b. Perpustakaan}

Dengan adanya penelitian ini diharapkan Badan Perpustakaan Daerah Propinsi Daerah Istimewa Yogyakarta mengetahui evaluasi koleksi dengan metode conspectus sebagai alat penilaian untuk mengetahui kekuatan dan kelemahan koleksi yang standar.

c. Pengembangan Iptek

Sesuai dengan perkembangan zaman yang semakin maju maka perpustakaan harus selalu meningkatkan kualitas koleksi dengan informasiinformasi yang mutakhir.

\section{TINJAUAN PUSTAKA}

Tesis yang ditulis oleh Atikah Nuraini (1998) yang berjudul Evaluasi Koleksi Pada Pusat Dokumentasi Hak Asasi Manusia (HAM) di Indonesia: Penerapan Metode Checklist dan Conspectus, mengkaji tentang koleksi-koleksi pada pusat dokumentasi dan informasi (Pusdokinfo) Komnas HAM, Universitas Diponegoro (Semarang) dan Universitas Airlangga (Surabaya) dengan tujuan untuk menilai standar koleksi yang dimiliki Pusdokinfo di tengah meningkatnya topik-topik seputar Hak Asasi Manusia. Hasil penelitian yang diperoleh adalah koleksi bidang Hak Asasi Manusia pada Komnas HAM dan Univesitas Airlangga (Surabaya) berada pada kisaran 0-3b, pada koleksi Komnas HAM koleksi berbahasa Indonesia mendominasi lima peringkat di atas kekuatan koleksi yakni tingkat 3 b sedangkan koleksi berbahasa Inggris mendominasi tingkat dibawah $3 \mathrm{~b}$, di Universitas Diponegoro (Semarang) koleksi berada pada kisaran 0-1b. Hal ini disebabkan oleh manajemen koleksi yang tidak berjalan secara normal.

Penelitian lain dilakukan oleh Wishnu Hardi (2005) berjudul Kajian Koleksi Bidang Linguistik Dengan Metode Conspectus di Perpustakaan Fakultas Ilmu Pengetahuan Budaya Universitas 
Indonesia. Penelitian ini bertujuan untuk mendeskripsikan keadaan aktual koleksi buku khusus subjek Linguistik Umum di Perpustakaan Fakultas Ilmu Pengetahuan Budaya Universitas Indonesia. Hasil penelitian menunjukan bahwa koleksi subjek Linguistik di Perpustakaan Fakultas Ilmu Pengetahuan Budaya Universitas Indonesia berada pada kisaran la sampai 2b. Analisis bahasa pada subjek linguistik memperlihatkan bahwa mayoritas koleksi untuk tiap kelas memiliki indikator $\mathrm{E}$ yang berarti bahan berbahasa Inggris mendominasi.

Simpulan dari penelitian di atas menunjukan peta kekuatan dan kelemahan terhadap koleksi-koleksi yang ada di perpustakaan dengan metode conspectus. Metode conspectus adalah penilaian terhadap koleksikoleksi berdasarkan subjek dengan menggunakan skema klasifikasi Library of Congress (LC) dan skema klasifikasi Dewey dengan menandai alfa numerik yang mengindikasikan tingkat korelasi dan cakupan bahasa koleksi. Sedangkan penelitian yang akan penulis lakukan dengan metode conspectus sama dengan tujuan diatas yaitu mengetahui peta kekuatan dan kelemahan koleksi, tetapi subjeknya pada semua kolcksi dengan mengambil sepuluh kelas utama yang terdapat pada skema klasifikasi Dewey di Badan Perpustakan Daerah Propinsi Daerah Istimewa Yogyakarta periode pengadaan tahun 2003. Lebih jelasnya penulis akan menjelaskannya pada penerapan metode conspectus baik pada perpustakaan umum maupun perpustakaan perguruan tinggi.

\section{LANDASAN TEORI}

\section{Metode Conspectus}

Menurut pendapat WLN (Western Library Network) Collection Assesment Manual (2001:13), Michalak (1994: 98), Pendit (1986: 67) serta Hernon (1998: 1) metode conspectus adalah memberikan penilaian dengan cara evaluasi koleksi untuk mengetahui kekuatan dan kelemahan koleksi dengan kode 0-5 untuk tingkat koleksi dan cakupan bahasa yang telah ditentukan.

Paul Mosher (1985: 17) mengidentifikasikan beberapa keuntungan yang bisa diperoleh dalam kegiatan evaluasi koleksi:

1. Mengetahui cakupan, kedalaman, dan kelengkapan koleksi

2. Membantu perencanaan pengembangan koleksi

3. Membantu pengambilan keputusan kebijakan pengembangan koleksi

4. Mengukur efektivitas kebijakan pengembangan koleksi

5. Menentukan kualitas koleksi

6. Meningkatkan nilai koleksi dengan mengetahui kelemahan-kelemahan yang ada.

Agar tidak terjadi kesalah pahaman penulis akan membatasi dengan teori-teori yang akan digunakan pada penelitian ini yaitu dengan teori Western Library Network (WLN) Collection Assesment Manual 4 Th, karena penjelasan lebih spesifik tentang karakteristik dan elemen dari conspectus serta penulis akan terapkan ke dalam sepuluh kelas utama yang ada pada skema Klasifikasi Persepuluhan Dewey, menurut DDC 21 (1996) sepuluh klas utama yaitu:

O00 Karya Umum

100 Filsafat dan Psikologi

200 Agama

300 Ilmu-ilmu Sosial

400 Bahasa

$500 \mathrm{Ilmu}$-ilmu Murni (Pasti/Alam)

600 Ilmu-ilmu Terapan (Teknologi)

700 Kesenian, Hiburan, Olahraga

800 Kesusasteraan 
900 Geografi dan Sejarah Umum

Teori Western Library Network (WLN) Collection Assesment Manual 4 Th, juga menjelaskan lebih spesifik tentang karakteristik dan elemen dari conspectus, yaitu:

1. Struktur

Struktur conspectus disusun secara hirarkis mulai dari pembagian divisi yang luas, dari subjek umum sampai pembagian subjek yang sangat spesifik. Perpustakaan dapat menggunakan salah satu atau seluruh hirarki ini. Struktur conspectus adalah sebagai berikut:

a) Divisi adalah hirarki yang paling pertama dari conspectus. Dalam WLN Conspectus terdapat 24 divisi yang tidak diatur berdasarkan skema klasifikasi.

b) Kategori adalah pembagian lebih lanjut dari divisi. Terdapat 500 penjabaran kategori yang diidentifikasi berdasarkan skema kasifikasi LC maupun Dewey.

c) Subjek adalah hirarki yang ketiga karena lebih spesifik dan terdiri dari 4000 subyek.

2. Kode Standar

Conspectus menggunakan nilai tingkatan numerik untuk memberikan gambaran mengenai kekuatan koleksi (Current Collection), tingkat pertumbuhan (Acquisition Commitment), dan tujuan koleksi (Collection Goal). Penilaian numerik menggunakan indikator skala 0-5 dimana masingmasing level adalah kode standar yang menjelaskan jenis aktivitas yang dapat didukung oleh tingkat koleksi (collection level).

a) Tingkat Pertumbuhan (Acquisition Commitment / $A C$ ), menjelaskan tingkat pertumbuhan koleksi. AC merefleksikan tingkat aktivitas aktual mengenai sejauh mana koleksi berkembang dan bukan level rekomendasi dari kebijakan pengembangan koleksi.

b) Tujuan Koleksi (Collection Goal / CG), mengindikasikan kebutuhan informasi aktual dan kebutuhan informasi yang dapat diantisipasi berdasarkan misi, program, dan pengguna perpustakaan. Indikator pada kegiatan ini merefleksikan penambahan atau penghapusan kurikulum yang mendorong perubahan prioritas pengembangan koleksi pada perpustakaan.

c) Kekuatan (Current Collection / CL), menggambarkan kekuatan koleksi relatif dalam suatu area subjek tertentu. Kekuatan koleksi meliputi seluruh bahan literatur dalam berbagai format seperti: monograf, jurnal, mikroform, bahan audio-visual, peta, dan lain sebagainya. Termasuk juga bahan literatur yang dikatalog maupun yang tidak dikatalog khusus yang tidak disirkulasikan serta koleksi yang disirkulasi. Penilaian CL mendeskripsikan sumber daya perpustakaan secara menyeluruh. Tingkat koleksi (collection level) meliputi berkisar pada angka $0-5$ dengan pengertian sebagai berikut:

\section{Kode Cakupan Bahasa}

Cakupan bahasa sangat berkaitan erat dengan level koleksi. Selain itu, representasi bahan berbahasa Inggris dan bahasa lainnya merupakan salah satu dimensi penting dalam menjelaskan keadaan intensitas koleksi menurut kode bahasa.

4. Evaluator atau keterangan dari pustakawan

Evaluator ini digunakan sebagai pelengkap dari penilaian numerik terhadap koleksi-koleksi yaitu penjelasan tentang gambaran kekuatan khusus atau 
Tabel 1

Tingkat Koleksi (collection level)

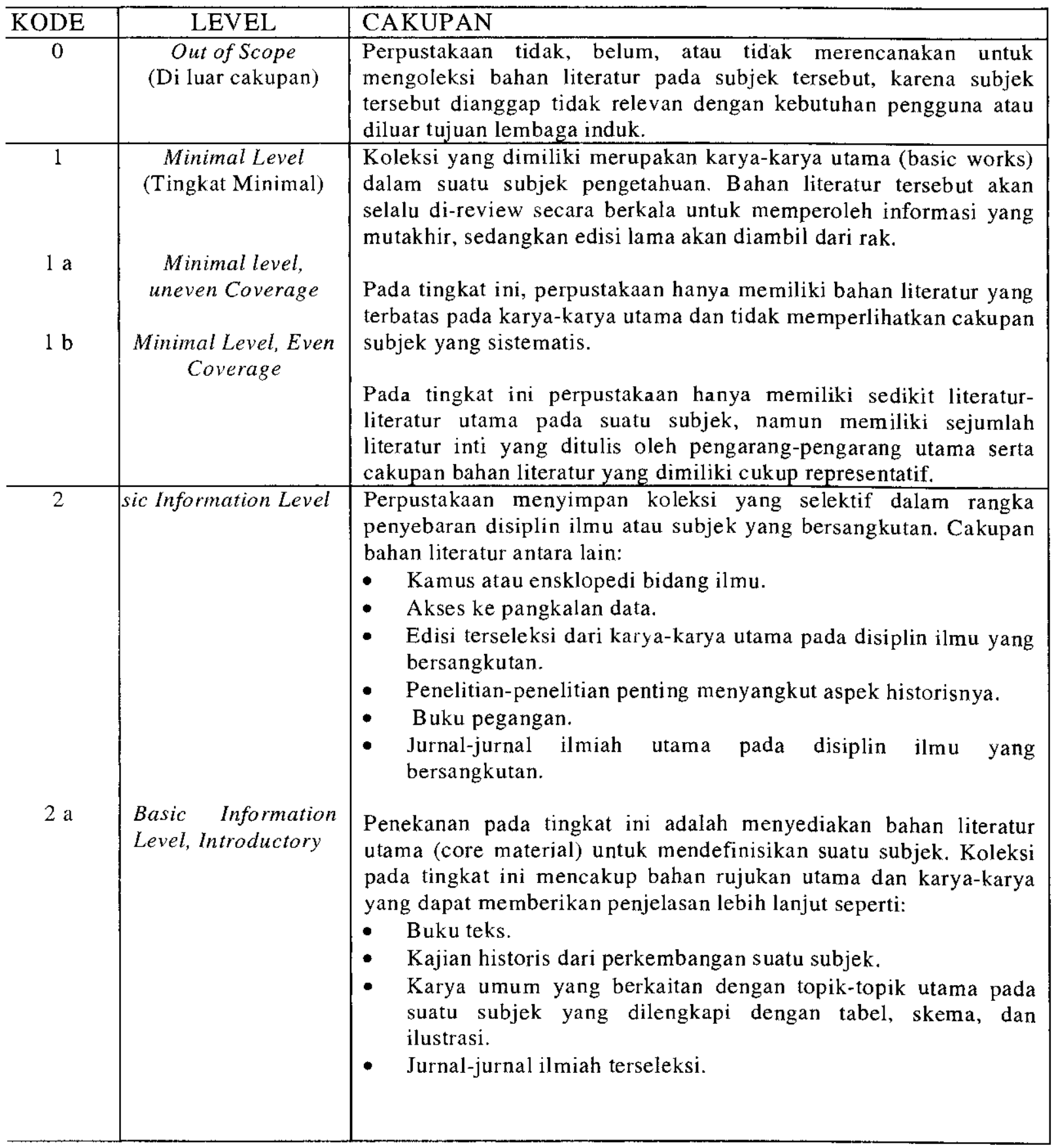


Tabel 1 (lanjutan)

Tingkat Koleksi (collection level)

\begin{tabular}{|c|c|c|}
\hline KODE & LEVEL & CAKUPAN \\
\hline $2 b$ & $\begin{array}{l}\text { Basic Information } \\
\text { Level, Advance }\end{array}$ & $\begin{array}{l}\text { Pada tingkat ini bahan literatur yang dimiliki hanya disediakan dalam } \\
\text { rangka pengumpulan informasi dasar tentang suatu subjek atau pengantar } \\
\text { bagi mahasiswa ban.. Pada tahap yang lebih lanjut ini, perpustakaan } \\
\text { mengoleksi bahan literatur dasar tentang subjek tertentu dengan cakupan } \\
\text { yang lebih luas dan lebih dalam untuk mendefinisikan dan } \\
\text { memperkenalkan suatu subjek. Karya-karya dasar dalam bentuk: } \\
\text { - Buku teks. } \\
\text { - Kajian historis, bahan literatur rujukan berkaitan dengan topik-topik } \\
\text { tertentu dari suatu subjek. } \\
\text { Jurnal-jurnal ilmiah yang selektif. Informasi dasar tahap lanjut yang } \\
\text { disediakan untuk mendukung mata kuliah dasar mahasiswa, di samping } \\
\text { memenuhi kebutuhan informasi dasar bagi universitas. }\end{array}$ \\
\hline 3 & $\begin{array}{c}\text { Study/Instructional } \\
\text { Support Level }\end{array}$ & $\begin{array}{l}\text { Yang ditekankan pada tingkat ini adalah bahan literatur yang dikoleksi } \\
\text { perpustakaan harus mendukung suatu disiplin ilmu. Bahan literatur yang } \\
\text { tersedia meliputi cakupan yang lebih luas untuk karya-karya utama dalam } \\
\text { berbagai format, sejumlah bahan retrospektif yang bernilai klasik, koleksi } \\
\text { yang lengkap dari karya-karya penulis penting pada suatu disiplin ilmu, } \\
\text { koleksi terpilih untuk karya-karya penulis sekunder, jurnal-jurnal terpilih } \\
\text { untuk cakupan subjek, akses menuju pangkalan data CD ROM, dan bahan } \\
\text { rujukan utama yang berisi bibliografi yang mendukung subjek yang } \\
\text { bersangkutan. }\end{array}$ \\
\hline $3 a$ & $\begin{array}{l}\text { Study/Instructional } \\
\text { Support Level, } \\
\text { Introductory }\end{array}$ & $\begin{array}{l}\text { Tingkat ini merupakan subdivisi dari tingkat } 3 \text { yang memberikan sumber } \\
\text { dalam rangka memelihara cabang pengetahuan dari suatu subjek. Koleksi } \\
\text { pada tahap ini sama dengan apa yang tercakup pada tingkat } 3 \text { yang } \\
\text { meliputi karya-karya utama dari suatu bidang disiplin ilmu dalam berbagai } \\
\text { format., bahan literatur retrospektif klasik, jurnal-jurnal utama dari suatu } \\
\text { subjek, akses menuju pangkalan data CD ROM, serta bahan rujukan yang } \\
\text { mencakup informasi bibliografis yang berhubungan dengan bidang } \\
\text { disiplin ilmu yang bersangkutan. Yang menjadi perbedaan dengan tingkat } \\
\text { sebelumnya adalah meskipun bahan literatur mendukung perkuliahan } \\
\text { program sarjana dan program kajian mandiri namum tidak cukup untuk } \\
\text { mendukung program magister. }\end{array}$ \\
\hline $3 b$ & $\begin{array}{l}\text { Study/Instructional } \\
\text { Support Level, } \\
\text { Advance }\end{array}$ & $\begin{array}{l}\text { Pada tingkat ini, koleksi mencakup bahan literatur yang dianggap } \\
\text { memenuhi syarat untuk memelihara suatu bidang disiplin ilmu. Koleksi } \\
\text { meliputi jurnal-jurnal utama dari topik-topik primer dan sekunder dari } \\
\text { suatu subjek, bahan literatur penting retrospektif, literatur substantif yang } \\
\text { memberikan kedalaman kajian untuk kepentingan riset dan evaluasi, akses } \\
\text { menuju pangkalan data CD ROM, bahan rujukan yang berisi sumber } \\
\text { bibliografis utama pada suatu subjek. Pada tingkat ini, bahan literatur } \\
\text { sudah memadai untuk program sarjana dan magister. }\end{array}$ \\
\hline
\end{tabular}




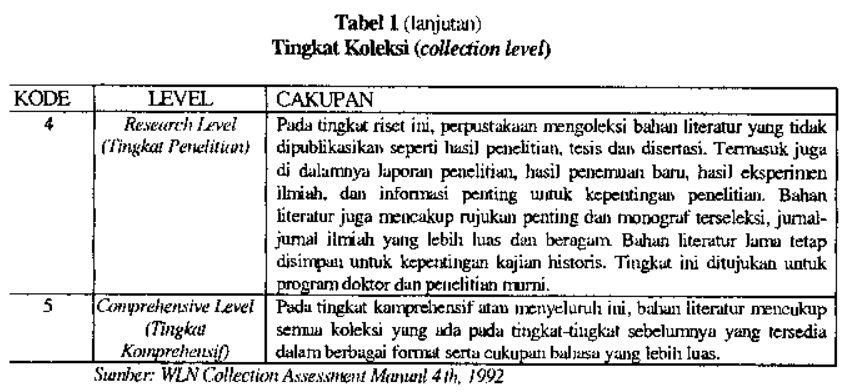

batas area subjek atau aktifitas pengoleksian karena

Tabel 2

Indikator Cakupan Bahasa

\begin{tabular}{|c|c|l|}
\hline KODE & JENIS & PENGERTIAN \\
\hline E & English & $\begin{array}{l}\text { Bahan literatur berbahasa Inggris } \\
\text { mendominasi, sedangkan koleksi } \\
\text { dalam bahasa lain hanya tersedia } \\
\text { sedikit atau bahkan tidak sama sekali. }\end{array}$ \\
\hline F & $\begin{array}{c}\text { Selected non-English } \\
\text { Languages }\end{array}$ & $\begin{array}{l}\text { Bahan literatur yang bukan berbahasa } \\
\text { Inggris tersedia secara terseleksi } \\
\text { untuk melengkapi bahan literatur } \\
\text { berbahasa Inggris. }\end{array}$ \\
\hline W & $\begin{array}{c}\text { Wide Selection } \\
\text { Languages }\end{array}$ & $\begin{array}{l}\text { Seleksi yang luas dari koleksi dalam } \\
\text { berbagai bahasa dan tidak ada } \\
\text { kebijakan membatasi bahan literatur } \\
\text { berdasarkan bahasa tertentu }\end{array}$ \\
\hline Y & $\begin{array}{c}\text { One-Non English } \\
\text { Longuage }\end{array}$ & $\begin{array}{l}\text { Bahan literatur didominasi oleh salah } \\
\text { satu bahasa selain bahasa Inggris. }\end{array}$ \\
\hline Simlter: WLNCollection Assessment Manual 4th, 1992
\end{tabular}

penentuan level conspectus dapat dilakukan oleh evaluator baik yang berasal dari dalam perpustakaan (inside evaluator) ataupun dari luar perpustakaan (outside evaluator). Penilaian yang dilakukan oleh evaluator berdasarkan kualitas koleksi dalam konteks nasional serta diperlukannya evaluator untuk menentukan indikator tingkatan koleksi dan cakupan bahasa. University of Wyoming. Collection Assesment. Http://www-lib.uwyo/cdo/collass.htm.

\section{Latar Belakang Sejarah Metode Conspectus}

Metode conspectus belum dikenal oleh kalangan masyarakat mungkin juga dikalangan pustakawan sendiri, maka dari itu penulis akan menjelaskan tentang sejarah metode conspectus.
Metode conspectus muncul sebagai upaya manajemen perpustakaan-perpustakaan riset di Amerika Serikat dalam menyiasati peningkatan kebutuhan informasi yang pesat ditengah terbatasnya anggaran perpustakaan. Selain itu metode conspectus muncul ketika Stielow (1986:27) melakukan evaluasi koleksi University of Maryland College. Para mahasiswa Departemen Ilmu Informasi dan Perpustakaan melakukan evaluasi koleksi dengan fokus pada subjek Seni, kesusasteraan Inggris, Musik, dan Sejarah. Tahapan evaluasi dijalankan dengan melakukan wawancara kepada staf pengajar, survai kurikulum, mengecek bibliografi dan menentukan tingkatannya dalam RLG Conspectus. Permasalahan muncul ketika para mahasiswa menemukan kesulitan dalam menghubungkan pandangan staf pengajar mengenai koleksi dan tingkat-tingkat pada conspectus. Ia menuturkan bahwa metode ini tidak merefleksikan keadaan perpustakaan yang sesungguhnya.

Penggunaan metode conspectus sebagai salah satu pendekatan dalam evaluasi koleksi ini ditekankan juga oleh American Library Association. Dalam ALA Guide for Written Collection Policy Statements edisi revisi tahun 1989 bahwa metode conspectus sangat dianjurkan menerima kekuatan (strongly recommended) untuk semua jenis perpustakaan. Skema pembagian subjek RLG (Research Library Group) atau Pacific Northwest Conspectus dapat dijadikan kerangka kerja untuk penyusunan kebijakan pengembangan koleksi perpustakaan (American Library Association, 1989:29).

Research Group Libraries (RLG) merintis konsep dan infrakstruktur evaluasi koleksi berdasarkan metode conspectus pada awal tahun 1980-an. RLG Conspectus pada awalnya dibuat untuk mendukung inventarisasi bahan literatur perpustakan-perpustakaan riset serta mengukur kekuatan koleksi (collection 
strength) dan intensitas koleksi (collection intensity). Upaya ini direalisasikan dengan melakukan survai menggunakan lembar kerja yang mengacu pada skema klasifikasi Library of Congress (RLG, 2004). Selain mengukur kekuatan koleksi perpustakaan, metode ini digunakan untuk memfasilitasi kerja sama dan saling berbagi sumber daya informasi di antara para anggotanya (RLG, 2004). Metode conspectus juga dimanfaatkan sebagai dasar pertimbangan jasa pinjam antarperpustakaan, pengelolaan dana, kebijakan pengembangan koleksi, alat akreditasi, serta prioritas preservasi (Munroe, 2004: 181).

The Research Libraries Group (RLG) itu sendiri didirikan pada tahun 1974 yang merupakan konsorsium dari Perpustakaan Umum Harvard, Columbia, dan New York, yang mengembangkan conspectus sebagai alat untuk menilai koleksi perpustakaan. RLG Conspectus disusun berdasarkan divisi, kategori subjek, dan kelompok subjek. Dua puluh empat divisi yang merepresentasikan cakupan disiplin ilmu seperti Seni dan Arsitektur, Ilmu Informasi dan Perpustakaan, Sejarah, dan Biologi. Divisi-divisi tersebut kemudian dibagi menjadi 100 kategori subjek dan kategori subjek dibagi lagi menjadi 7000 kelompok subjek. (Nissonger, 1992: 120).

\section{Penerapan Metode Conspectus di Perpustakaan}

Metode Conspectus mempunyai tujuan utama yaitu untuk memfasilitasi pengambilan keputusan tentang pengembangan koleksi dengan berdasarkan kebutuhan informasi pengguna dengan ketersediaan dana yang dimiliki. Evaluasi bahan literatur dengan metode Conspectus dapat menggambarkan pemetaan skala prioritas dalam hal kebijakan pengembangan sumber daya informasi perpustakan. (Fragkou-Batsiou, 2005).

Penerapan metode conspectus pernah dilakukan oleh Fragkou tahun 1998, meliputi lima Perpustakaan di Yunani khusus untuk subjek fisika, kimia, dan informatika. Ini merupakan penerapan metode conspectus untuk yang pertama kalinya untuk koleksi jurnal ilmiah. Fragkou menggunakan conspectus sebagai alat analisis deskriptif tentang kedalaman, keluasan, format, dan kelengkapan koleksi jurnal bidang fisika, kimia, dan informatika yang mengarah pada evaluasi koleksi pada ke lima perpustakaan di Yunani tersebut. Gambaran mengenai koleksi inti (core list) adalah tujuan akhir dari penelitian oleh Fragkou. Saat ini metode ini mulai secara luas diterapkan di perpustakaan-perpustakaan Yunani yang menjadi dasar pertimbangan utama dalam pembentukan jaringan atau kerja sama antarperpustakaan. Metode conspectus sebagai model evaluasi koleksi yang membantu penyusunan kebijakan pengembangan koleksi dapat menjadi dasar bagi kerja sama perpustakaan yang lebih luas dalam konteks lokal, wilayah, negara, dan internasional (IFLA, 2001: 2).

Penerapan metode conspectus pada tingkat nasional secara lebih terarah pemah dilakukan oleh Scott dalam proyek inventarisasi koleksi perpustakaanperpustakaan di Kanada. Dalam proyek yang dikenal dengan National Plan for Collection Inventories, setiap perpustakaan di Kanada mengimplementasikan conspectus dalam menginventarisasi koleksi yang mereka miliki. Dalam hal ini Scott menyatakan bahwa conspectus diperlukan untuk tujuan kerja sama antarperpustakaan, pengembangan koleksi, dan preservasi. Tingkat-tingkat dalam conspectus dimodifikasi dan dikoordinasikan oleh National Library of Canada (Marianne, 1987: 289-290).

Pada tahun 1995, Sullivan melakukan evaluasi koleksi untuk bidang Ilmu Alam di University of Melbourne, Australia dengan menggunakan metode conspectus. Dalam penelitiannya, ia melakukan teknik pengecekan koleksi di rak (shelf-scanning), pengecekan daftar koleksi buku (list checking), dan wawancara dengan para staf akademik. Kekuatan 
koleksi yang diperoleh merefleksikan kajian displin ilmu yang dominan di University of Melborne di mana Teknik, Botani, dan Zoologi merupakan koleksi yang ada pada level 4 (riset).

Kesimpulan dari penerapan-penerapan metode Conspectus kebanyakan dilakukan pada perpustakaan Perguruan Tinggi karena untuk mengetahui kekuatan spesialisasi subjek, sedangkan di perpustakaan umum adalah sebagai alat untuk menilai kekuatan koleksi perpustakaan yaitu sesuai dengan visi, misi serta tujuan dari perpustakaan.

\section{Kelebihan-kelebihan metode conspectus antara lain:}

Sebagai bahan pertimbangan dalam akuisisi dan preservasi koleksi, mendukung efisiensi pemanfaaatan anggaran, acuan akreditasi, dan menjembatani antara kebutuhan informasi pengguna serta koleksi yang tersedia. Sedangkan kelebihankelebihan dibandingkan dengan metode evaluasi yang lainnya adalah :

1. Penentuan skala prioritas bahan literatur dari institusi yang mengoleksinya sehingga memudahkan komunikasi dan perbandingan di antara institusi-institusi untuk bisa bekerja sama.

2. Memfokuskan perhatian pustakawan pada pertanyaan mendasar tentang kualitas koleksi serta hubungan antara kekuatan koleksi dan pemanfaatannya.

3. Dapat memperbandingkan kualitas subjek yang berbeda pada satu institusi yang sama serta meningkatkan persepsi pustakawan terhadap penentuan skala prioritas koleksi.

4. Sebuah sarana komunikasi antara opini pustakawan dan koleksi yang dimiliki.
5. Berperan sebagai katalis untuk program pengembangan koleksi yang sistematis meskipun ada beberapa pihak yang berpendapat bahwa analisis evaluasi koleksi dengan metode conspectus lebih sesuai untuk keadaan yang akan datang dan bukan keadaan aktual. (Mount Saint Vincent University, 2004):

\section{Kelemahan-kelemahan metode conspectus antara} lain:

1. Kelemahan utama metode conspectus terletak pada subjektivitas yang menjadi terus menjadi pertanyaan sepanjang sejarah penerapannya.

2. Kelemahan lain adalah cakupan format literatur yang terbatas hingga subjektivitasnya di mana dikatakan sesungguhnya conspectus bukan merupakan suatu data melainkan ekspresi opini (are not data, but expression of opinion).

Penjelasan mengenai kelebihan dan kelemahan metode Conspectus dapat menjadi sebuah tolak ukur agar penerapan metode dalam evaluasi koleksi perpustakaan dapat efisiens dalam mengantisipasi kelemahan yang ada.

\section{Definisi Operasional}

Menurut WLN Collection Assesment Manual 4 Edition (1992) Metode conspectus adalah seperangkat kode standar, alat, survai yang digunakan untuk memberikan penilaian koleksi secara sistematis. Metode conspectus merupakan metode untuk mengukur koleksi secara kualitatif. Dan metode conspectus adalah salah satu pendekatan dengan evaluasi koleksi.

Menurut Nuraini (1998: 37) mengukur intensitas merupakan tingkatan kekuatan koleksi yang ditandai dengan kedalaman, keluasan dan kelengkapan 
koleksi pada suatu perpustakaan. Yang didasarkan pada standar yang dibuat oleh ALA Guide for Written Policities dengan menggunakan kode 1 - 5 dan metode yang dikenal adalah metode conspectus.

Menurut Prytherch (1990: 174) koleksi adalah kumpulan buku atau bahan literatur lainnya yang terdiri dari satu subjek atau lebih, atau bahan literatur yang sejenis atau lebih dari satu jenis, yang dikoleksikan oleh seseorang maupun organisasi.

Menurut Soeatminah (1992: 21) monograf merupakan jenis koleksi yang berupa buku yaitu wadah informasi yang berwujud lembaran kertas, membahas satu masalah, yang dicetak, dilipat, dan diikat bersama pada punggungnya, serta diberi sampul.

Menurut Soeatminah (1992: 21) pengadaan merupakan langkah awal dari proses tidak ada menjadi ada atau menambalı koleksi yang sudah ada dengan cara membeli, meminta dan menerima sebagai hadiah, tukar menukar atau menerbitkan sendiri.

Badan Perpustakaan Daerah Propinsi Daerah Istimewa Yogyakarta adalah perpustakaan daerah yang ada di Propinsi Daerah Istimewa Yogyakarta dan mempunyai tugas melayani seluruh Iapisan masyarakat tanpa membedakan tingkat usia, tingkat sosial, tingkat pendidikan dan lain-lain. Perpustakaan Daerah mempunyai tugas-tugas sebagai berikut:

1. Mengumpulkan dan menyusun bahan pustaka yang menyangkut wilayah dan semua jenis koleksi, jenis penerbitan di wilayah yang bersangkutan, termasuk bahan-bahan perpustakaan lainnya.

2. Memberikan pelayanan dan mendayagunakan bahan pustaka.

3. Menyelenggarakan pelayanan referensi

4. Memelihara bahan pustaka

5. Menyusun katalog induk majalah
6. Membantu pelaksanaan pemberian bimbingan teknis perpustakaan

7. Melaksanakan urusan tata usaha dan urusan rumah tangga perpustakaan daerah. (Sulistyo, 1994: 37).

Sepuluh klas utama klasifikasi DDC (Dewey Decimal Clasification) yaitu mulai dari klas $000-$ 900, meliputi : 100 Karya Umum, 100 Filsafat \& Psikologi, 200 Agama, 300 Ilmu-ilmu Sosial, 400 Bahasa, 500 Ilmu-ilmu Murni (Pasti/Alam), 600 Ilmuilmu Terapan (Teknologi), 700 Kesenian - Hiburan OR, 800 Kesusasteraan, 900 Geografi \& Sejarah Umum.

Berkaitan dengan tujuan penelitian adalah penerapan metode conspectus untuk mengukur intensitas koleksi monograf yaitu untuk mengetahui kekuatan dan kelemahan koleksi monograf di Badan Perpustakaan Daerah Propinsi Daerah Istimewa Yogyakarta untuk sepuluh kelas utama pada skema klasifikasi Dewey periode pengadaan tahun 2003.

\section{METODE PENELITIAN}

Metode penelitian merupakan suatu jalan atau cara yang dipergunakan dalam upaya menemukan, mengembangkan dan menguji kebenaran suatu pengetahuan dengan jalan mengadakan penelitian di lapangan. Penulis menggunakan beberapa metode yang digunakan dalam penelitian adalah sebagai berikut:

\section{Jenis Penelitian}

Dalam penelitian ini digunakan penelitian deskriptif kuantitatif yaitu jenis penelitian yang menggambarkan atau uraian atau suatu kejadian sejelas mungkin dengan data-data yang ada. Penelitian yang dilakukan penulis adalah penerapan terhadap koleksi monograf sepuluh kelas utama dengan metode conspectus yang dijadikan acuan dan yang menilai 
pada koleksi-koleksi monograf adalah evaluator dalam (input evaluator).

Sesuai dengan tujuan penelitian, maka penelitian ini menggunakan teknik penilaian terhadap koleksi (collection-based technique) dengan metode conspectus. Metode conspectus dipilih dengan alasan:

1. Penjabaran subjek dalam conspectus yang mengacu pada skema klasifikasi LC dan DDC dapat memberikan deskripsi singkat mengenai keadaan koleksi.

2. Koleksi aktual dan pola pengoleksian bahan literatur dapat digambarkan melalui indikatorindikator yang memungkinkan perbandingan secara langsung.

3. Metode ini dapat memberikan peta kekuatan dan kelemahan koleksi secara langsung melalui penjabaran subjek disiplin ilmu yang diteliti beserta tingkat indikator yang menyertainya sebagai informasi keadaan aktual koleksi.

4. Metode ini juga dapat menggambarkan koleksi inti (core collection) dari perpustakaan. Penjabaran disiplin ilmu dalam penjabaran subjek kerangka kerja conspectus sangat tepat diterapkan pada perpustakaan perguruan tinggi karena lebih sesuai dengan keadaan koleksi perpustakaan (University of Wyoming, 2004).

\section{Tempat dan Waktu Penelitian}

Penelitian ini dilakukan di Badan Perpustakaan Daerah Propinsi Yogyakarta. Sedangkan waktu pelaksanaan penelitian ini dari tanggal 10 desember 2006 sampai 10 januari 2007.

\section{Populasi}

Menurut Arikunto (2002: 108) Populasi adalah keseluruhan subjek penelitian, atau jumlah keseluruhan dari unit analisa yang cici-cirinya akan diduga. Populasi dalam penelitian ini adalah koleksi monograf sepuluh kelas utama pada klasifikasi persepuluhan Dewey dan akan diambil tahun 2003 yaitu dengan jumlah 102.000 judul buku.

\section{Sampel}

Dalam penelitian ini menggunakan tehnik Random Sampling. Menurut Arikunto (1993: 107) yaitu tehnik pengambilan secara acak.

Peneliti mengambil sampel jumlah koleksi monograf tahun 2003 di Badan Perpustakaan Daerah Propinsi Daerah Istimewa Yogyakarta adalah 102.000 judul. Selanjutnya jika jumlah subjeknya besar dapat diambil antara $10-20 \%$ atau $20-25 \%$ atau lebih tergantung setidak-tidaknya dari kemampuan peneliti dilihat dari waktu, tenaga dan biaya (Arikunto 2002: 112). Atas pertimbangan teori diatas dan karena keterbatasan kemampuan biaya, tenaga dan waktu, maka sampel yang diambil peneliti adalah $50 \%$ dari masing-masing golongan klasifikasi.

\section{Varibel Penelitian}

Variabel menurut Arikunto (2002: 96) adalah objek penelitian, atau apa yang menjadi titik perhatian suatu penelitian. Penelitian ini bersifat deskriptif survai. Hasil dan kesimpulan dari deskriptif pada umumnya hanya mendeskripsikan konsep dan variabel yang diteliti (Sugiono, 2003: 53).

Tabel 3

Sampel Kalekvi Badan Perpustakan Dacrah Propinsi DYY tahn 2003

\begin{tabular}{|c|c|c|}
\hline Golongan Klasifikasi & Populasi & Sampel \\
\hline 000 Karya Umum & 9.000 judul & 4.500 \\
\hline 100 Filsafat dan Psikologi & 5.000 judul & 2500 \\
\hline 200 Agama & 7.000 judul & 3500 \\
\hline 300 Imu-ilmu Sosial & 29.000 juchl & 14500 \\
\hline 400 Bahasa & 6.000 judul & 3.000 \\
\hline 500 Ilmrilmu Mmini (Pasti/Alam) & 6.000 judul & 3.000 \\
\hline 600 Ilmt-ilmu Terapan (Teknologi) & 21.000 judul & 10500 \\
\hline 700 Kesenian, Hiburan, Olahraga & 5.000 juchul & 2.500 \\
\hline 800 Kesusasteraan & 7.000 judul & 3.500 \\
\hline 900 Geografi dan Sejarah Umum & 7.000 juctul & 3500 \\
\hline Total & 102000 judul & 51.000 \\
\hline
\end{tabular}

Duta Kdeksi Budan Penpustakoum Doendh Propinsi DIY Periode Pengadon tahn 2003 
Variabel yang akan diteliti adalah distribusi golongan klasifikasi, kekuatan dan kelemahan koleksi, cakupan kronologis dan analisis bahasa.

\section{Teknik Pengumpulan Data}

\section{Survei}

Menurut Faisal (1995: 22) adalah proses yang akan ditujukan pada sejumlah besar individu atau kelompok, unit yang ditelaah. Dalam penelitian ini penulis mencatat data koleksi dari klas utama berdasarkan klasifikasi persepuluhan Dewey 000-900 yang ada di Badan Perpustakaan Daerah Propinsi Daerah Istimewa Yogyakarta periode pengadan tahun 2003.

\section{Observasi}

Menurut Subagyo (1997: 63) adalah pengamatan langsung yang dilakukan secara sengaja, sistematis mengenai fenomena sosial dan gejal-gejala yang ada untuk memperkuat data-data yang diperoleh melalui survei. Penulis langsung datang kemudian mencatat data koleksi pada buku inventaris periode pengadaan tahun 2003.

\section{Wawancara (interview)}

Penulis menggunakan wawancara terpimpin (guide interview), dengan pedoman tanya jawab yang ditetapkan sebelumnya (Marzuki, 1977: 62). Penulis melakukan wawancara dengan pustakawan yang ada di Badan Perpustakaan Daerah Propinsi DIY bagian pengadaan. Pedoman wawancara terlampir

\section{Evaluator}

Dalam metode conspectus, diperlukan evaluator untuk menentukan indikator tingkat koleksi dan cakupan bahasa. Penilaian yang diberikan evaluator berdasarkan kualitas koleksi dalam konteks nasional (Universitas of Wyoming, 2007).

Peneliti menggunakan evaluator yang berasal dari dalam perpustakaan (inside evaluator) yaitu pustakawan Badan Perpustakaan Daerah Propinsi DIY sebagai pelengkap nilai numerik terhadap koleksi dan deskriptif untuk menjelaskan kekuatan khusus atau batas koleksi area subjek maupun aktivitas pengoleksian.

\section{Analisis Data}

Dalam penelitian ini digunakan penelitian deskriptif kuantitatif yaitu jenis penelitian yang menggambarkan uraian atau suatu kejadian sejelas mungkin dengan data-data yang ada dengan cara data koleksi dikumpulkan dan diolah menggunakan tehnik tabulasi dengan menyajikan hasil penelitian pada tabel distribusi yang hasilnya prosentasekan lalu di deskripsikan. Adapun data kuantitatif, dianalisis dengan metode statistik sederhana, dengan rumus :

a. Distribusi klas utama persepuluhan Dewey

$\mathrm{P}=$ Jumlah koleksi yang ada Dada buku inventaris $X 100 \%$ Total Koleksi

b. Kekuatan dan kelemahan koleksi

Hasil dari kekuatan dan kelemahan koleksi ini dinilai oleh evaluator sesuai dengan hasil persentase distribusi serta penerapannya pada tingkat koleksi dari tingkat 1 - 5 (lihat tabel 1).

c. Cakupan kronologis

Merupakan tahun terbitan dari koleksi monograf yang kemudian dipersentase yaitu dengan cara :

$\mathrm{P}=\mathrm{Jumlah}$ tahun terbit yang ada pada buku inventaris X $100 \%$ Total Tahun Terbit

\section{d. Analisis bahasa}

Merupakan hasil penilaian dari evaluator untuk mengetahui bahasa apa yang dimiliki di 
perpustakaan dalam penerapan kode bahasa dan untuk lebih jelasnya lihat tabel 2.

\section{HASIL PENELITIAN}

Dalam penelitian ini digunakan penelitian deskriptif kuantitatif yaitu jenis penelitian yang menggambarkan uraian atau suatu kejadian sejelas mungkin dengan data-data yang ada dengan cara data koleksi dikumpulkan dan diolah menggunakan tehnik tabulasi dengan menyajikan hasil penelitian pada tabel tabel distribusi dan persentase lalu di deskripsikan

Analisis data dalam metode conspectus dijelaskan oleh WLN Collection Assesment dengan point-point sebagai berikut:

1. Jenis dan format koleksi seperti jurnal, koleksi referen, CD ROM, bahan audio visual, dan lain sebagainya.

2. Jumlah judul yang signifikan yang merepresentasikan koleksi inti perpustakaan dengan tidak memperhatikan jumlahnya serta perbandingan monograf dengan terbitan berseri.

3. Usia koleksi dan cakupan kronologis termasuk penentuan nilai tengah

4. Bahasa (cakupan bahasa)

5. Kondisi fisik koleksi

6. Kontinuitas terbitan berseri

7. Persentase distribusi koleksi yang ada pada standar serta materi koleksi pendukung seperti literatur yang berisi kritik, komentar dan intepretasi.

8. Penggunaan statistik sirkulasi dan jumlah tahunan pinjam antar pustaka

9. Anggaran pengadaan koleksi tahunan per judul atau per serial.
10. Modifikasi analisis penelitian dalam bentuk pembatasan-pembatasan point diatas dan disesuaikan dengan keadaan koleksi klas utama Badan Perpustakaan Daerah, yaitu:

a. Koleksi-koleksi hanya jenis monograf klas utama klasifikasi persepuluhan Dewey periode pengadaan tahun 2003.

b. Penulis mengabaikan jenis koleksi non buku dan kondisi fisik, kontinuitas terbitan berseri, penggunaan statistik sirkulasi dan jumlah tahunan pinjam antar pustaka, anggaran pengadaan koleksi tahunan per judul atar per serial, karena point-point ini lebih berkaitan dengan pemanfataan koleksi, sedangkan tujuan penulis adalah hanya mengetahui intensitas koleksi yaitu kekuatan dan kelemahan koleksi.

\section{Distribusi klas utama klasifikasi persepuluhan Dewey}

Dalam mengklasifikasi koleksi monograf Badan Perpustakaan Daerah Propinsi DIY menggunakan klasifikasi Dewey, karena klasifikasi Dewey sudah umum dipakai oleh perpustakaanperpustakaan. Penulis menyesuaikan dengan keadaan koleksi monograf di Badan Perpustakaan Daerah Propinsi DIY dan distribusi kelas utama dijelaskan dalam tabel berikut:

Dari hasil tabel penulis juga mengurutan peringkat $1-3$ ada dua klas utama yang jumlah persentasenya sama yaitu $22 \%$ meliputi distribusi klas 000 (karya umum) dan distribusi klas 300 (ilmu-ilmu sosial) ini menempati urutan pertama. Sedangkan peringkat kedua distribusi klas 600 (ilmu-ilmu terapan / teknologi) dengan persentase $16 \%$. Selanjutnya peringkat ketiga juga ada dua klas yaitu 200 (agama) dan 900 (geografi dan sejarah umum) dengan jumlah persentase $10 \%$. 
Tabel 4

Distribusi klas utama klasifikasi persepuluhan Dewey

\begin{tabular}{|c|c|c|c|c|}
\hline No & No klas & Golongan & Jumlah & persentase \\
\hline 1 & 000 & Karya Umum & 673 & $22 \%$ \\
\hline 2 & 100 & Filsafat \& Psikologi & 258 & $8 \%$ \\
\hline 3 & 200 & Agama & 309 & $10 \%$ \\
\hline 4 & 300 & Ilmu-ilmu Sosial & 657 & $22 \%$ \\
\hline 5 & 400 & Bahasa & 44 & $2 \%$ \\
\hline 6 & 500 & Ilmu-ilmu Murni (Pasti/Alam) & 100 & $3 \%$ \\
\hline 7 & 600 & Ilmu-ilmu Terapan (Teknologi) & 499 & $16 \%$ \\
\hline 8 & 700 & Kesenian, Hiburan, OR & 99 & $3 \%$ \\
\hline 9 & 800 & Kesusasteraan & 295 & $10 \%$ \\
\hline 10 & 900 & Geografi \& Sejarah Umum & 116 & $4 \%$ \\
\hline \multicolumn{3}{|r|}{ Total } & 3080 & 100 \\
\hline
\end{tabular}

Dari data dari Badan Perpustakaan Daerah Propinsi DIY melakukan sistem pengadaan koleksikoleksi melalui hadiah yaitu menerima hadiah dari instansi lain dari seluruh indonesia serta dari penerbitpenerbit di Propinsi DIY berdasarkan Perda no. 12 tahun 2005. Selain hadiah dengan pembelian yaitu menggunakan sistem pengadaan barang dan jasa berpedoman pada Kepres no 80 tahun 2003 beserta perubahannya.serta menjaring melalui sekolah-sekolah dan perguruan tinngi yang ada di Propinsi DIY.

\section{Kekuatan dan kelemahan koleksi}

Setelah hasil diketahui dari semua koleksi yang dapat dilihat pada tabel 1 distribusi klas utama, kemudian untuk mengetahui kekuatan dan kelemahan koleksi monograf adalah penerapannya pada metode conspectus yaitu mengenai tingkat (level) koleksi (lihat tabel 1) dan tabel cakupan bahasa (lihat tabel 2 ).

Hasil evaluator merupakan penerapan dari hasil distribusi klas dengan tabel tingkat koleksi (0 5) dan tabel kode bahasa oleh pustakawan Badan Perpustakaan Daerah Propinsi DIY dan hasilnya adalah berkisar antara tingkat $1 \mathrm{bY}$ hingga tingkat $2 \mathrm{aY}$ dengan rincian sebagai berikut:

Tingkat lb yaitu Minimal Level yang berarti perpustakaan memiliki sedikit literatur-literatur utama pada suatu subjek, namun memiliki sejumlah literatur inti yang ditulis oleh pengarang utama serta cakupan bahan literatur yang dimiliki cukup representatif meliputi Klas 100 (Filsafat \& Psikologi), Klas 400 (Bahasa), Klas 700 (Kesenian, Hiburan, OR) dan 900 (Geografi \& Sejarah Umum).

Tingkat 2 yaitu Basic Information Level yang berarti perpustakaan menyimpan koleksi yang selektif dalam rangka penyebaran disiplin ilmu atau subjek yang bersangkutan dan meliputi Klas 200 (Agama), Klas 500 (Ilmu-ilmu Murni (Pasti/Alam) dan Klas 600 (Ilmu-ilmu Terapan (Teknologi).

Tingkat 2a yaitu Basic Information Level yang berarti perpustakaan menyediakan bahan literatur

Tabel 5

Kekuatan dan kelemahan koleksi

\begin{tabular}{|l|l|l|l|l}
\hline No & $\begin{array}{l}\text { No } \\
\text { klas }\end{array}$ & Golongan & $\begin{array}{l}\text { Hasil } \\
\text { evaluator }\end{array}$ & Komentar \\
\hline 1 & 000 & Karya Umum & $2 \mathrm{aY}$ & Mutakhir \\
2 & 100 & Filsafat \& Psikologi & 1bY & Tidak Mutakhir \\
3 & 200 & Agama & $2 \mathrm{Y}$ & Mutakhir \\
4 & 300 & llmu-ilmu Sosial & $2 \mathrm{aY}$ & Mutakhir \\
5 & 400 & Bahasa & $1 \mathrm{bY}$ & Tidak Mutakhir \\
6 & 500 & Ilmu-ilmu Murni (Pasti/Alam) & $2 \mathrm{Y}$ & Tidak Mutakhir \\
7 & 600 & Ilmu-ilmu Terapan (Teknologi) & $2 \mathrm{Y}$ & Mutakhir \\
8 & 700 & Kesenian, Hiburan. OR & $1 \mathrm{bY}$ & Tidak Mutakhir \\
9 & 800 & Kesusasteraan & 2Y & Mutakhir \\
10 & 900 & Geografi \& Sejarah Umum & Tidak Mutakhir \\
\hline
\end{tabular}

utama (Core Material) untuk mendefinisikan suatu subjek dan meliputi Klas 000 (Karya Umum) dan Klas 300 (Ilmu-ilmu Sosial).

Huruf Y sendiri adalah merupakan jenis kode bahasa (One-Non English Language) yang berarti bahan literatur didominasi oleh salah satu bahasa selain bahasa Inggris. 
Keterangan mengenai mutakhir dan tidak mutakhimya koleksi ini berhubungan dengan cakupan kronologis sebuah koleksi. Penulis membatasi koleksi yang mutakhir adalah tahun terbit yang hasilnya lebih dari 10 (sepuluh) persen dari jumlah koleksi, sedangkan ketidak mutakhiran koleksi adalah yang hasilnya kurang dari 10 (sepuluh) persen.

Penulis berpendapat bahwa pada golongan 000 (karya umum) dan 300 (ilmu-ilmu sosial/ pendidikan) ini dapat dijadikan potensi untuk dikembangkan sebagai koleksi inti Badan Perpustakaan Daerah Propinsi DIY, karena Propinsi DIY merupakan kota pendidikan. Para evaluator juga menekankan adanya penambahan anggaran untuk memenuhi kebutuhan koleksi yang up to date serta variasi koleksi yang masih kurang memenuhi kebutuhan pemakai perpustakaan. (wawancara dengan pustakawan Badan Perpustakaan Daerah Propinsi DIY, tanggal 22 Desember 2006 jam 10.00 wib)

Sedangkan tujuan koleksi pada semua perpustakaan menginginkan pada tingkat $5 \mathrm{~F}$ yang berarti 5 adalah Comprehensive Level (Tingkat Komprehensif) artinya pada tingkat komprehensif atau menyeluruh ini, bahan literatur mencakup semua koleksi yang ada pada tingkat-tingkat sebelumnya yang tersedia dalam berbagai format serta cakupan bahasa yang lebih luas. F merupakan kode bahasa (Selected non-English Languages) yaitu bahan literatur yang bukan berbahasa Inggris tersedia secara terseleksi untuk melengkapi bahan literatur berbahasa Inggris. Untuk berada pada level $5 \mathrm{~F}$ mengindikasikan perlunya kerja keras perpustakaan dalam membenahi manajemen koleksinya.

Analisis penulis mengenai minimnya level conspectus koleksi monograf dikarenakan faktorfaktor :

1. Badan Perpustakaan Daerah Propinsi DIY sebagai perpustakaan umum koleksi- koleksinya belum sepenuhnya memenuhi kebutuhan pemakai.

2. Hampir semua koleksi monograf berbahasa Indonesia.

3. Badan Perpustakaan Daerah Propinsi DIY memiliki keterbatasan anggaran untuk pengadaan koleksi secara proporsional sehingga dalam melayani pemakai belum optimal. (wawancara dengan pustakawan Badan Perpustakaan Daerah Propinsi DIY, tanggal 22 Desember 2006 jam $10.00 \mathrm{wib}$ )

4. Teori metode conspectus cocok untuk diterapkan di Perpustakaan Perguruan Tinggi karena subjektif tetapi jika diterapkan di Perpustakaan Umum maka akan terlihat minimnya tingkat koleksi.

\section{Cakupan kronologis}

Cakupan kronologis untuk koleksi monograf di Badan Perpustakaan Daerah Propinsi DIY dapat disebut relevan, karena jumlah tahun terbitan yang mutakhir lebih dari $10 \%$ dan hasilnya dapat dilihat dari persentase distribusi cakupan kronologis dalam tabel 6.

Tabel 6

Cakupan kronologis

\begin{tabular}{|l|l|c|c|}
\hline No & Tahun terbit & Jumlah juhlul & Fersentase \\
\hline 1 & $<1990$ & 112 & $6 \%$ \\
2 & $1990-2000$ & 164 & $8 \%$ \\
3 & $2000-2001$ & 357 & $18 \%$ \\
4 & $2001-2002$ & 722 & $38 \%$ \\
5 & $2002-2003$ & 546 & $28 \%$ \\
6 & S.a(tidak ada tahun terbit) & 24 & $2 \%$ \\
\hline \multicolumn{2}{|r|}{ Total } & 1925 & 100 \\
\hline
\end{tabular}

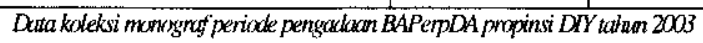

Dari hasil data yang ada di Badan Perpustakaan Daerah Propinsi DIY tentang terbitan koleksi monograf periode pengadaan tahun 2003 
didominasi oleh terbitan tahun 2002 dan 2003. Koleksi monograf di Badan Perpustakaan Daerah Propinsi DIY dapat dikatakan relevan, karena dalam pengadaan melalui cara mengumpulkan katalog dari setiap penerbit sehingga dapat mengetahui buku-buku yang tahun terbitannya baru. Disebutkan dalam WLN Collection Assessment (1992) bahwa kemutakhiran koleksi adalah $10 \%$ dari total koleksi dimana kemutakhiran koleksi adalah terbitan 5 tahun terakhir.

Penulis dalam mengumpulkan data menemukan s.a atau tidak diketahui tahun terbitnya yaitu $2 \%$. Kemudian terbitan yang 5 tahun terakhir pada periode pengadaan tahun 2003 yang menempati urutan pertama adalah tahun 2002 yaitu $38 \%$ dan urutan kedua adalah tahun 2002 yaitu $28 \%$ serta urutan yang ketiga adalah 2001 yaitu $18 \%$.

\section{Analisis bahasa}

Badan Perpustakan Daerah Propinsi DIY mempunyai koleksi monograf yang didominasi oleh terbitan berbahasa Indonesia akan tetapi penulis pernah menemukan koleksi monograf yang menggunakan bahasa Inggris dengan jumlah yang sedikit. Pada kenyataannya yang dimiliki Badan Perpustakaan Daerah Propinsi DIY koleksi monograf hampir semua berbahasa Indonesia. Sebab dalam sistem pengadaan di Badan Perpustakaan Daerah Propinsi DIY melalui penerbit-penerbit di Propinsi DIY.

\section{PENUTUP}

\section{Kesimpulan}

Setelah mengadakan penelitian dan menganalisis data, maka penulis dapat menarik kesimpulan sebagai hasil akhir dari penelitian. Adapun kesimpulannya sebagai berikut:

1. Badan Perpustakaan Daerah Propinsi DIY belum menerapkan metode conspectus dalam menilai kekuatan dan kelemahan koleksi monograf akan tetapi cukup dengan melihat daftar statistik pengadaan koleksi.

2. Intensitas koleksi monograf di Badan Perpustakaan Daerah Propinsi DIY nilai tertinggi adalah klas 300 (ilmu-ilmu sosial) dan klas 000 (karya umum).

3. Hasil evaluator yaitu pustakawan Badan Perpustakaan Daerah Propinsi DIY menilai untuk kekuatan koleksi dapat dilihat dari persentase distribusi ada 2 (dua) klas meliputi klas 300 (ilmu-ilmu sosial) 22\% dan klas 000 (karya umum) 22\% dan berada pada level $2 \mathrm{a}$ yaitu tingkat informasi dasar (Basic Information Level) yang berarti perpustakaan menyediakan bahan literatur utama (Core Material) untuk mendefinisikan suatu subjek. Sedangkan kelemahan koleksi ada 4 (empat) klas meliputi klas 100 (filsafat) $8 \%$, klas 900 (Geografi\&sejarah umum) $4 \%$, klas 700 (kesenian, Hiburan OR) $3 \%$ dan klas 500 (Bahasa) $2 \%$ yaitu berada pada level lb yaitu tingkat minimal (Minimal Level) yang berarti perpustakaan memiliki sedikit literatur-literatur utama pada suatu subjek, namun memiliki sejumlah literatur inti yang ditulis oleh pengarang utama serta cakupan bahan literatur yang dimiliki cukup representatif

4. Analisis bahasa yaitu kode $\mathrm{Y}$ adalah merupakan jenis kode bahasa (One-Non English Language) yang berarti bahan literatur didominasi oleh salah satu bahasa selain bahasa inggris.

5. Cakupan kronologis pada koleksi monograf sepuluh klas utama adalah terbitan tahun 2003 yang menempati urutan pertama adalah tahun 2002 yaitu $38 \%$ dan urutan kedua adalah tahun 2002 yaitu $28 \%$ serta urutan yang ketiga adalah 2001 yaitu $18 \%$. 
Saran

1. Sebagai perpustakaan umum daerah dalam menyikapi pengadaan perlu peningkatan kualitas koleksi yang berisi tentang informasiinformasi yang mutakhir untuk mencerdaskan pengetahuan pemakai. Serta pengadaan koleksi monograf bervarisi bahasanya agar tidak monoton satu bahasa saja dan sebaiknya dalam mengukur koleksinya menggunakan metode conspectus karena cara penilaiannya relatif sederhana dan tepat sasaran dalam mengetahui kekuatan dan kelemahan koleksi.

2. Frekuensi dari kekuatan koleksi tetap harus ditingkatkan serta penambahan bahasa koleksi.

3. Penelitian tentang metode conspectus dapat dilakukan kembali pada tahun-tahun sesudah tahun 2003 untuk mengetahui kekuatan dan kelemahan koleksi monograf sepuluh klas utama agar tercipta standar conspectus di Badan Perpustakaan Daerah Propinsi DIY.

\section{DAFTAR PUSTAKA}

Arikunto, Suharsimi. 2002. Metode Penelitian: Suatu Pendekatan dan Praktek. Jakarta: Rineka Cipta American Library Association. Resources and Technical Services Division. I989. Guide for Written Collection Policy Statements. 2 ed. Edited by Bonita Bryant. Chicago: American Library Association.

Faisal, Sanapiah. 1995. Format-Format Penelitian Sosial: Dasar-Dasar dan Aplikasi. Jakarta: Rajawali Press

Frgkou-Batsiou, Anna. 2005. "The Conspectus Method Application to Scientific" Journals: The Greek Case Study.
Hernon, Peter and Charles Mc CLure. 1988. Evaluation and Library Decision Making. New Jersey : Ablex Publishing

Hardi, Wisnu. 2005. "Kajian Koleksi Bidang Linguistik dengan Metode Conspectus di Perpustakaan Fakultas Imu Pengetahuan Budaya Universitas Indonesia". Depok: Universitas Indonesia. Skripsi

IFLA, International Library Association and Institution. 2001. "Guidelines For A Collection Development Policy Using The Conspectus Model". Http:// www.ifla.org/VIU/s14. akses 22 Desember 2006

Marzuki. 1977. Metodologi Riset. Yogyakarta: Fakultas Ekonomi UII

Matheson, Ann. Collection Level Deskription: A Review of Exiting Practice. http ://www.columbia.edu/cu/ lweb/services/colldev/collectiondepth.html akses 28 Desember 2006

Michalak, Sarah. 1994. "Planning Academic library Facilities : The Library will have the walls", (Journal of Library Administration Bvol. 20 No. 2. Mount Saint Vincen University Collection Development Policy Manual). http :// www.library.auckland.ac.nz/about/biblio/cdp/ cdpconsp.htm akses tanggal 25 Februari 2006

Mitchell, Joan S (editor). 1996. Dewey Decimal Clasification. Ed. 21. New York: Forest Press.

Munroe, H. Mary and Jennie E Ver Steeg. 2004. "The Decision-Making Process in Conspectus Evaluation of Collections: The Quest for Certainty", Library Quarterly April Vol. 74

Mosher, Paul. 1985. A National Scheme for Collaboration in Collection Development : The RLG-NCIP Effort, Recourse Sharing and Information Network. 
Mount Saint Vincent University. Collection Development Policy Manual. Http:// www.msvu.ca/Library/cdrV12.htm. Akses tanggal 26 November 2006

Nissonger, Thomas E. 1992. Collection Evaluation In Academic Libraries : A Literatur Guide and Annotated Bibliography. Colorado: Libraries Unlimited

Nuraini, Atikah, 1998, "Evaluasi Koleksi pada Pusat Dokumentasi Hak Asasi Manusia di Indonesia: Penerapan Metode Checklist dan Conspectus". Tesis.

Pendit S, Murtini, 1986, "Relevansi Antara Perpustakaan dan Koleksi Pustaka” Dalam Hasil Konggres 3 Ikatan Pustakawan Indonesia, Yogya, 22 - 24 September 1983. Editor Heddy Suprihadi, Jakarta: IPI

Perpustakaan Nasional RI. 2005. Tentang Petunjuk Teknis Jabatan Fungsional Pustakawan dan Angka Kreditnya. Jakarta: Perpustakan Nasional RI.

Prytech, Ray. 1990. Harrod's Librarians' Glossary: of Term Used in Librarianship, Documentation and the Book Crafts. England: Gower Publishing.

Scott, Marianne. 1987. "The National Plan for Collection Inventories", Canadian Library Journal 44 (October).

Soeatminah, 1992, Perpustakaan, Kepustakawanan dan Pustakawan. Yogyakarta: Kanisius

Subagyo, Joko. 1997. Metode Penelitian Dalam Teori dan Praktek. Jakarta: Gunung Mulia.

Sudijono, Anas. 2000. Pengantar statistik Pendidikan. Jakarta: Raja Grafindo Persada.

Sugiono. 2003. Metode Penelitian Bisnis. Bandung: Alvabeta
Sulistyo-basuki. 1994. Periodisasi Perpustakaan Indonesia. Bandung: Remaja Rosdakarya.

Sulivan, Shirley. 1995. Travails of Conspectus Oficer. http ://www/rlg.org/conspechist.html. akses tanggal 25 November 2006

Stiewlow, Federic J and Helen R Tibo. 1987. "Collection Analysis and The Humanities: A Practicum with The RLG Conscectus", Journal of Education for Library and Information Science 37 (Winter)

Universitas of Wyoming. Collection Assesment. $\mathrm{Http}: /$ /www-Lib.uwyo/cdo/collas.htm. Akses tanggal 10 Januari 2007

WLN. 2001. Collection Assesment Manual 4 Th,

H t t p / / w w w. g o o g l e.co.i d / search?hl=id\&q=wln+collection+assesment\&meta= Akses tanggal 22 Februari 2006 